\title{
USING BLOGS TO PROMOTE STUDENT INTERACTION AND LEARNING IN EFL CLASSES
}

\author{
Izela Habul-Šabanović \\ Faculty of Pedagogy, University of Sarajevo
}

\begin{abstract}
This paper addresses the application of a class blog in an EFL (English as a foreign language) teaching context in order to promote student interaction and learning. A weblog, or blog, is an interactive homepage easy to set up and manage, which permits publishing online. Although it was not initially provided for pedagogical purposes, a blog has a great potential to be used as a tool in EFL classes, especially to motivate students to engage in online exchanges, thereby expanding their language study and learning community beyond the walls of a physical classroom. This small scale action research explores the usefulness of incorporating a blog project into an EFL class as it provides an effective means of facilitating greater learner interaction and reflection on language skills development. A class blog was envisaged as an out-of-class project aimed at motivating students to practice language skills and communicate with others via this new computer-based learning platform outside the classroom. The participants for this study were the third and fourth year students $(n=52)$ of the Pedagogical Faculty in Sarajevo attending an EFL elective course. The research mainly focused on the students' attitudes and perceptions of using a class blog to support their English language learning and foster student interaction in an online learning community. The project lasted for two semesters and data were collected from students through a questionnaire at the end of the term. The results of the questionnaire reveal that students had an overall positive attitude towards using a class blog as an appropriate medium for practicing both their language and social skills.
\end{abstract}

Keywords: blogs, EFL, student interaction and learning, online learning community, students' attitudes and perceptions 


\section{Introduction}

Modern information and communication technologies not only influence the ways in which we share and gather information, or communicate, but they also inevitably bring about changes in the ways we learn and teach as well. The invention of Web 2.0 applications (e.g. Wikies, blogs, social networking, etc.) has emphasized the interactivity and social aspect of technology usage, so it has fundamentally changed the way people interact on the Internet, making them contributors of information, instead of consumers. The Internet users are thus enabled to create its content independently, publishing their own thoughts and opinions and exchanging their experiences with other people from all over the world, thus creating a new online platform for virtual interaction and collaboration.

Web 2.0 technologies have a great potential to introduce innovations in foreign language teaching, especially English, which no doubt can be considered a language of modern information and communication technologies. Unlike the traditional education model mostly relying on the 'talk and chalk' method, Computer Assisted Language Learning (CALL) supported with these cutting-edge and sophisticated, but still user-friendly technologies, offers numerous opportunities to promote students' active and autonomous learning and foster their critical thinking and social interaction. The teaching and learning process is thus replaced outside the walls of a traditional classroom into a cyber space of a virtual learning environment, where all communication takes place via computer, whether in real or asynchronous time.

This paper explores the use of a blog, as a representative example of Web 2.0 technologies, in English as a foreign language (EFL) teaching, emphasizing its great potential for the improvement of the quality of interaction between EFL teachers and students and the raise of motivation to learn English. This paper first provides some background information and a brief overview of the relevant literature on the educational value of blogs in EFL teaching. We start with the definition of a blog, its basic characteristics and types, and explore the numerous possibilities for its application in EFL teaching. This paper also reports on a research project where a class blog was integrated into an EFL course at the university level, along with the survey targeted to examine the participants' perception of the learning experiences afforded by the use of a class blog as a means to support social interaction and learning motivation, and also to supplement in-class learning activities.

\section{Blogs}

A blog (short for weblog) is a frequently updated website which mostly functions as a personal online journal. It is 'easy-to-create' and 'easy-to-maintain' 
(Pinkman 2005: 14) since it requires only a minimum technical background and basic access to the Internet to make use of a software that enables users to create, design and maintain their own blog with ease. Hosting websites such as Blogger. com, first introduced in 1999 and offering a free-of-charge and simple automatized procedure of creating a blog, have made this effective medium of communication even more popular. According to Godwin-Jones (2003: 14), ' they offer a great deal of flexibility and the potential for creativity in the construction of the site, yet still feature the ease of use of a template-based system.' Blogs differ from other types of computer-mediated communication (CMC), i.e. they are unique websites in the form of electronic journals where authors post their writings in reverse chronological order, with the most recent at the top, and thus create a new topic for discussion for each post (Richardson 2006) and they are innovative in that they require interaction, i.e. 'for blog users, or bloggers, the computer is simply the medium for communication' (Pinkman 2005: 14). Kennedy (2003: 1) defines blogs as 'part Web site, part journal, part free-form writing spaces [that] have the potential to enhance writing and literacy skills while offering a uniquely stylized form of expression.

Huffaker (2004: 1) distinguishes these basic features of a blog: (i) instant publishing of text or graphics to the Web without sophisticated technical knowledge, (ii) ways for people to provide comments or feedback to each blog post, (iii) the opportunity to archive past blog posts by date, and (iv) hyperlinks to other bloggers. A typical blog is thus a combination of text, images, audio, video and other multimedia contents, also including links to other blogs, web pages and media related to its topic. These specific features distinguish blogs from other forms of CMC, especially because they support creative expression and provide new opportunities for people to present themselves online and share their experiences, opinions or creations with millions of other internet users worldwide. Ever since they first appeared in 90s, having the form of a personal online diary at the time, blogs have evolved in more sophisticated forms mostly due to the advancement of 'tools' for arranging the web content. Blogs have become popular platforms for presenting new ideas, online discussion and exchange of thoughts, therefore their number and purpose is growing fast every day, e.g. blogs of popular magazines and TV broadcasts, blogs of public people, blogs of political campaigns, comercial blogs, travel blogs, etc.

Based on their specific features, blogs can be distinguished in different types, e.g. individual or collaborative, personal or thematic, etc. Some authors, like Herring et al. (2005: 6), suggest a somewhat different classification, according to the primary purpose of a blog: (1) a personal journal, presenting the author's personal life and attitudes, (2) a filter, in which the author offers links and commentaries on the contents of other web pages, (3) a know- 
ledge $\log$ or $\mathrm{k}-\mathrm{log}$, in which the basic content consists of information and observations focused on an external topic, a project or a product, and (4) a mixed blog, which combines the functions of the three previously mentioned types.

Blogs have a great potential to be effectively and purposefully applied in education, especially in language teaching, 'because of their multimedia features, simple web publishing, interactivity, and ability to support cooperative and autonomous learning' (Ahluwalia et al. 2011: 30). Campbell (2003) suggests three types of blogs that could be used in language teaching: (1) the tutor blog, lead by the teacher and whose content refers to the curriculum, information about the course, useful links to other related contents on the internet, assignments, homework, etc.; students can also make comments on their teacher's posts; (2) the learner blog, lead by individuals, or smaller cooperative groups of students, and representing students' own online space for individual expression, and at the same time a great opportunity to practice reading and writing through managing a personal blog or posting comments on other students' blogs; (3) the class blog, as a common online space for teachers and students, for out-of-class discussions, supporting project learning, and even international exchanges while connecting with other students and teachers from all over the world.

\section{Blogs in EFL education}

Although blogs were not initially intended to satisfy pedagogical purposes, their simple user-friendly interface makes them an effective medium in educational settings, especially in the foreign language classroom. Carney (2009: 299) suggests that 'theoretically speaking, blogs offer promise in several key areas of language education including motivation, authenticity, collaboration and literacy. Generally, blogs foster interaction and collaboration between teachers and students as they provide a viable online space for exchange and discussions. Teachers are given opportunities to design their course in an innovative and creative way, and therefore motivate and encourage their students for additional learning, critical thinking and research even outside the classroom. Blogs can also enhance the sense of community between students while they exchange information about themselves and their interests, and respond to their classmates' posts. Blogging also provides opportunities for shy students to 'be heard' in class discussions on blogs.

Assuming the fact that blogs have only recently gained their popularity in education, the possibilities and the results of their application have not been sufficiently explored yet (Pinkman, 2005, Carney, 2009). However, the number of studies indicating their usefulness is growing fast. For example, Huffaker (2004) suggests that the effectiveness of blogs in education is achieved by their promotion 
of critical literacy skills, including reading, writing, self-expression, reflection and creativity. Campbell (2003: 1) confirms the educational value of blogs by stating that 'similar to an open journal, the accumulation of writings and other content creates both a record of learning and a resource for others'. Many authors report about the positive attitudes of students towards the use of blogs in English language teaching, e.g. Ahluwalia et al. (2011) and Blackstone et al. (2007). Teaching and learning via blogs are not limited by time and space, since communication can be asynchronuos, and what is more, learning becomes more autonomous and independent, more student-centered and adapted to his/her needs and interests. According to Weiler (2003: 74): 'Weblogs can become an extension of the classroom, where discussions and collaborations continue long after the bells have sounded and students have left for home. This makes Weblogs an excellent vehicle for student-centered learning.' Lee (2011: 102-103) reports about promoting learning autonomy and intercultural competence through blogging in education: 'Overall, students found that blogging supported self-directed learning, as they individually and socially constructed meanings to develop their intercultural knowledge and skills. According to the post-survey findings, blogging promoted learner autonomy through self-regulation and self-management.' Blogs can also be beneficial for teachers, e.g. they provide oportunities for better communication and cooperation with students, easier and faster exchange of information and teaching materials, possibilities for work with students who are not able to attend regular classess for whatever reason, the use of blogs as an electronic portfolio for students' writings and easier assessment of their progress, possibilities for cooperation with parents and other teachers, etc.

Blogs have numerous advantages for their usage in EFL teaching and it is up to teachers and their skillfulness and creativity, bearing on mind their own and their students' needs, how to make best use of blogs in their teaching. Many authors offer some useful ideas on how to use blogs in English language teaching, e.g. for practice in reading and writing (Zhang, 2009, Ducate and Lomicka, 2008, Ward, 2004), for study in literature (Morrison, 2008), to foster reflection and social interaction and cooperation (Ray \& Hocutt, 2006), as a journal run by teachers and students, providing space for comments, reactions and reflections on what has been done in class to be published; an online space to exchange intercultural projects and represent an online community of teachers and students (Dieu, 2004), etc.

Keeping in mind the idea that effective learning environments require some form of social interaction, blogs can be a good example since they provide its users a sense of connection with their peers (Richardson, 2003). Many researchers have pointed out the importance of active exchanges with others to enhance student performance and satisfaction (Gunawardena \& Zittle, 1997; Moore \& 
Kearsley, 1996; etc.). According to Richardson (2003: 5), blogs are 'a way to communicate with students ..., 'manage' the knowledge that members of the school community create. Blogs also provide space to deliver course content, including syllabi, assignments, links, or other updates (Downes, 2004; Roberts, 2003). Thus, while posting on their blogs, educators and other users potentially create an on-line resource for their peers to refer to for guidance (Campbell, 2003).

According to Moore and Kearsley (1996), there are three types of interaction that allow students to achieve effective learning in distance learning environments: (i) learner - content interaction, (ii) learner - instructor interaction, and (iii) learner - learner interaction. While focusing on these three types of interactions, teachers may overcome potential shortfalls caused by a 'transactional distance' in such learning environments, which is due to the fact that teachers and learners do not interact in the same physical and temporal space. All three types of interactivity promote engaged learning and help develop collaborative learning experiences. Gunawardena and Zittle (1997), researchers in the area of social presence and computer-mediated conferencing, refer to the collaborative aspect of computer-mediated learning as 'social presence, which is defined as the experience of immediacy and intimacy in social exchanges and found to be a strong predictor of student satisfaction with the class. Based on these findings, the current study focused on the creation of an online learning environment via a Class blog that offers opportunities for learnerlearner interaction and creates an atmosphere in which students are motivated to learn and become part of a learning community with their classmates.

\section{Methodology \\ Rationale of the study}

This project was initiated as a small scale action research study. The author implemented a blog project into an elective EFL course in order to fulfill the following objectives:

- To determine the usefulness of using blogs to foster social interaction between students and encourage out-of-class learning.

- To provide students with a suitable platform to express their attitudes and opinions, engage in critical thinking and discussion with others, while reflecting on topics that had been covered in class and repeated on our Class Blog.

- To motivate students for autonomous learning and additional reading or research on topics discussed.

- To provide insights for other EFL professionals into the possibilities of using blogs in the foreign language classroom. 
Generally, the EFL course goals were as follows:

- To increase students' motivation to learn and use English as much as possible.

- To develop students' confidence in using English more both in-class and outof-class.

- To improve students' English language skills - speaking, writing, reading and listening, and strengthen their ability to use English more efficiently.

- To provide more practice in grammar and vocabulary as well.

- To develop students' communication skills and encourage interaction and cooperation among them both in in-class and out-of-class activities

- To encourage students for autonomous learning and taking the responsibility for their own progress in learning English.

- To enhance their critical-thinking and creativity.

- To improve their web searching skills and make them use new technology tools both for their English learning and professional needs.

- To improve their English for Academic Purposes, providing more practice in academic writing, research skills in the field using new technology, discussion strategies and formal oral presentations.

\section{Participants and context}

The participants were 52 third-year and fourth-year Bachelor level students of the Pedagogical Faculty in Sarajevo, at the Department of Elementary School Teaching and the Department of Preschool Teaching. They were all females, their average age was 20-22, and their mother tongue Bosnian. They learned EFL and it was a compulsory General English course at the first year of their studies with only 2 lessons ( $2 \times 45$ minutes) per week in both semesters. At the third and the fourth year it was one of their elective courses, also represented with only 2 lessons $(2 \mathrm{x}$ 45 minutes) per week each semester. It was a mixed-level group related to their proficiency in English. Although their average level of English was pre-intermediate to intermediate, there were some of them either below or above this level. Our lessons were held in the computer lab, fully equipped and with a stable internet connection.

\section{Procedure}

The concept of a Blog was first introduced to the target group of students through a Power Point presentation, providing details about its design and usage, explaining the basic rules for successful blogging and posting comments on a blog, and discussing the benefits of using a blog in language teaching. For the purpose of this project, a special Class Blog - 'Let Us Learn English Online' - was designed 
and used. The students were instructed how to access our Class Blog and its content and how to post their comments.

After the introductory session, the project was conducted as an out-of-class project. Our Class Blog was used for further discussion and posting comments on various topics, based on what we did in-class. The students were also encouraged to do some individual research and study independently at home, using the links provided on our Class Blog. The students were responsible for writing at least one comment on their own for each topic of discussion, and commenting on at least two or three of their classmates' comments. The contents of their entries were to be based on provided topics of discussion and expressing their personal attitudes and opinions. The project lasted for two semesters. At the end of the project period, the students were asked to complete a questionnaire anonymously to evaluate the Class Blog project.

\section{The Survey Instrument}

In order to collect data on the students' attitudes and perceptions of using a class blog to support their English language learning and foster student interaction in an online learning community, the researcher designed a post-project questionnaire to be completed at the end of the term. There were 20 items in total on the survey instrument, mostly focusing on student perceptions of social interaction (Statements 1-9 and 11-13) and learning via a Class Blog (Statements 10 and 1417), but also including a few statements (Statements 18-20) aimed to determine overall class satisfaction. Respondents were asked to mark their agreement with the statements on five-point Likert-type scales ranging from 1 (strongly agree) to 5 (strongly disagree). All of the 52 students completed the questionnaire.

\section{Results and discussion}

Results of the survey, as presented in Table 1, indicate that overall student perceptions of social interaction and learning via a Class Blog as well as class satisfaction were positive, i.e. most students agreed or somewhat agreed with the statements describing high levels of social exchange and learning via a Class Blog.

\begin{tabular}{|l|l|l|l|l|l|l|}
\hline Statement & $1(\%)$ & $2(\%)$ & $3(\%)$ & $4(\%)$ & $5(\%)$ & $\begin{array}{l}\text { NA } \\
(\%)\end{array}$ \\
\hline $\begin{array}{l}\text { (1) A Class Blog is an excellent medium for } \\
\text { social interaction. }\end{array}$ & 84.61 & 7.69 & 1.92 & 1.92 & 3.84 & 0 \\
\hline
\end{tabular}




\begin{tabular}{|c|c|c|c|c|c|c|}
\hline $\begin{array}{l}\text { (2) I think there was a lot of interaction } \\
\text { between } \\
\text { the participants in this course. }\end{array}$ & 38.46 & 42.30 & 13.46 & 1.92 & 1.92 & 1.92 \\
\hline $\begin{array}{l}\text { (3) I felt comfortable introducing myself and } \\
\text { conversing with other students via our Class } \\
\text { Blog. }\end{array}$ & 65.38 & 26.92 & 0 & 1.92 & 5.76 & 0 \\
\hline $\begin{array}{l}\text { (4) This interaction enabled me to form a sense } \\
\text { of being part of an online learning community. }\end{array}$ & 71.15 & 15.38 & 5.76 & 1.92 & 3.84 & 1.92 \\
\hline $\begin{array}{l}\text { (5) I felt comfortable to actively participate in } \\
\text { our course discussions. }\end{array}$ & 76.92 & 11.53 & 3.84 & 3.84 & 3.84 & 0 \\
\hline $\begin{array}{l}\text { (6) I really enjoyed the exchanges with other } \\
\text { students. }\end{array}$ & 82.69 & 7.69 & 1.92 & 1.92 & 5.76 & 0 \\
\hline $\begin{array}{l}\text { (7) I am satisfied with the quality of exchanges } \\
\text { that occurred in this class. }\end{array}$ & 65.38 & 23.07 & 5.76 & 1.92 & 3.84 & 0 \\
\hline $\begin{array}{l}\text { (8) The discussions we had in our Class Blog } \\
\text { were valuable to me. }\end{array}$ & 75 & 17.30 & 1.92 & 0 & 5.76 & 0 \\
\hline $\begin{array}{l}\text { (9) I felt that my point of view was acknow- } \\
\text { ledged by other participants in the course. }\end{array}$ & 38.46 & 44.23 & 7.69 & 3.84 & 3.84 & 0 \\
\hline $\begin{array}{l}\text { (10) I learned a lot from other participants in } \\
\text { the course. }\end{array}$ & 57.69 & 32.69 & 1.92 & 3.84 & 3.84 & 0 \\
\hline $\begin{array}{l}\text { (11) I got to know the other participants better } \\
\text { through our online discussions. }\end{array}$ & 44.23 & 40.38 & 9.61 & 3.84 & 1.92 & 0 \\
\hline (12) I learned to value other points of view. & 73.07 & 19.23 & 0 & 3.84 & 3.84 & 0 \\
\hline $\begin{array}{l}\text { (13) I am satisfied with the level of social inter- } \\
\text { action in this online course. }\end{array}$ & 69.23 & 23.07 & 3.84 & 1.92 & 1.92 & 0 \\
\hline $\begin{array}{l}\text { (14) I was able to learn through the medium of } \\
\text { a Class Blog. }\end{array}$ & 73.07 & 17.30 & 1.92 & 5.76 & 1.92 & 0 \\
\hline $\begin{array}{l}\text { (15) I think that my level of learning English } \\
\text { has improved in this online course. }\end{array}$ & 65.38 & 17.30 & 9.61 & 3.84 & 3.84 & 0 \\
\hline $\begin{array}{l}\text { (16) I was stimulated to do additional reading } \\
\text { or research on topics discussed in our Class } \\
\text { Blog. }\end{array}$ & 55.76 & 30.76 & 5.76 & 5.76 & 1.92 & 0 \\
\hline $\begin{array}{l}\text { (17) The diversity of topics presented in our } \\
\text { Class Blog prompted me to participate in the } \\
\text { discussions. }\end{array}$ & 53.84 & 34.61 & 5.76 & 3.84 & 1.92 & 0 \\
\hline $\begin{array}{l}\text { (18) Overall, our Class Blog met my learning } \\
\text { expectations. }\end{array}$ & 67.30 & 25 & 0 & 3.84 & 3.84 & 0 \\
\hline $\begin{array}{l}\text { (19) Overall, I enjoyed having been a member } \\
\text { of this class. }\end{array}$ & 86.53 & 5.76 & 1.92 & 1.92 & 3.84 & 0 \\
\hline $\begin{array}{l}\text { (20) As a result of this experience, I would like } \\
\text { to participate in another online course in the } \\
\text { future. }\end{array}$ & 80.76 & 9.61 & 3.84 & 1.92 & 3.84 & 0 \\
\hline
\end{tabular}

1 - 'strongly agree'; 2 - 'somewhat agree'; 3 - 'undecided'; 4 - 'somewhat disagree'; 5 - 'strongly disagree'; NA - 'no answer' 
The following results relate to assessments of student perceptions of social interaction via a Class Blog. As for the statements with the highest percentage of responses 'strongly agree', $84.61 \%$ of students strongly agreed that a Class Blog is an excellent medium for social interaction and $82.69 \%$ of students really enjoyed the exchanges with other students. Seventy-five percent of respondents strongly agreed that the discussions on our Class Blog were valuable to them and $76.92 \%$ of students felt comfortable to actively participate in our course discussions. Furthermore, $73.03 \%$ of students strongly agreed that they learned to value other points of view and $71.15 \%$ of students strongly agreed that this interaction via a Class Blog enabled them to form a sense of being a part of an online learning community. Besides that, $65.38 \%$ of students strongly confirmed that they felt comfortable introducing themselves and conversing with other students via our Class Blog, with the same percantage of those who were satisfied with the quality of exchanges that occurred in the class. Overall, $69.23 \%$ of students were satisfied with the level of social interaction in this online course. These results seem to indicate that our structured online discussions via a Class Blog positively affected student perceptions of social interaction between the participants of this EFL class. Our Class Blog has proved to be a useful tool to foster student active participation and personal involvement in our class discussions and to make them feel that they are part of a learning community. Generally, the results may imply student perceptions of high overall class interaction and class satisfaction.

Nevertheless, there were two statements related to student perceptions of social interaction via our Class Blog which were not equally ranked with a high percentage of responses 'strongly agree' compared to the other statements of this category. Namely, $42.30 \%$ of students somewhat agreed with the statement that there was a lot of interaction between the participants of this course, whereas $38.46 \%$ of students strongly agreed with that. Similarly, $44.23 \%$ of respondents somewhat agreed that they felt their point of view was acknowledged by other participants in the course, but still $38.46 \%$ of them strongly agreed with that. Besides that, $44.03 \%$ of students strongly agreed with the statement that they got to know the other participants better through these online discussions, whereas $40.38 \%$ of students somewhat agreed with that. These percentages are particularly noteworthy in that students perceived that the amount of interaction between the participants in this online course was slightly lower than expected and they were not fully satisfied with the level of acknowledgement of their points of view by other participants. These results could be explained by the fact that this was a pilot project mainly envisaged as an out-of-class activity to support English language learning and foster student interaction, and it lasted only for two semesters. Class Blog discussions followed our in-class activities and they obliged students to spend some extra time outside the classroom to prepare for and actively participate in a purposeful online exchange with their col- 
leagues. Obviously, they perceived this new type of activity as something completely different from what they were used to do, not only in their English classes, but in other study courses as well. Although it was a positive change and they did their best to become active members of an online learning community via our Class Blog, they need more time and opportunities to get used to this innovative EFL approach. Although students confirmed that they enjoyed the exchanges with other group members and that the online class discussions were valuable to them, they still did not value our Class Blog as highly in terms of peer-to-peer learning opportunities. The results indicate that most students strongly agreed that they learned to value other points of view (73.07\%), but they still need more confirmation and acknowledgement from their peers, and more opportunities to get to know them better.

The following results relate to assessments of student perceptions of learning via a Class Blog. Generally, $73.07 \%$ of students strongly agreed that they were able to learn through the medium of a Class Blog and $65.38 \%$ of students strongly agreed that their level of learning English improved in this online course. Besides that, the results indicate that our Class Blog motivated students to learn since 55.76\% of students strongly agreed that they were stimulated to do additional reading or research on topics discussed and $53.84 \%$ of students confirmed that the diversity of topics presented in our Class Blog prompted them to participate in the discussions. It is also noteworthy to observe that $57.69 \%$ of students strongly agreed that they learned a lot from other participants in the course, which is a clear indication that our Class Blog was valued highly in terms of providing opportunities to learn from others. These results seem to support the idea that a Class Blog could be used as an appropriate medium for English language learning and practice in EFL classes.

The results related to the overall class satisfaction reveal that students had a positive attitude towards using a Class Blog to foster their learning and social interaction with their peers. Specifically, $67.30 \%$ of students strongly agreed that our Class Blog met their learning expectations and $86.53 \%$ of students enjoyed having been a member of this class. As a result of this experience, $80.76 \%$ of respondents strongly agreed that they would like to participate in another online course in the future.

\section{Conclusion}

As has been stated above, the aim of this small scale study was to assess the attitude of a group of EFL students towards the integration of a Class Blog in the EFL classroom and its potential to enhance social interaction between students and support their EFL learning. The results of the evaluation questionnaire not only showed the positive response of all students in the group towards using a Class Blog in the EFL classes, but also confirmed that they are more motivated and in- 
terested in learning when engaged in meaningful tasks with the authentic material.

A Class Blog has a great potential to be used as a tool in EFL classes, providing opportunities to motivate students to engage in online exchanges with their peers and expand their language study and learning community beyond the walls of a physical classroom. Students experience a greater feeling of learning and achievement as they are given chances to learn both by themselves and from their peers. They are expected to construct their own knowledge and become responsible for their own progress, but they also share a common goal with the others in the group. A Class Blog provides them a unique opportunity to enjoy rich and repeated exchanges with their classmates which may enhance students' overall class experience, being part of a larger learning community and enjoying the class in general. At the same time, the teacher gets a new role, as he/she is no longer a presenter of information but a facilitator to assist and direct his/her students.

A Class Blog has proved to be a powerful teaching and learning tool in a modern EFL classroom and it can be effectively used to promote student interaction while they actively participate in an online learning community. Besides, a Class Blog offers numerous opportunities for EFL learning and language skills development. The results showed that most students are motivated to learn if they are provided with authentic tasks and resources, and given opportunities to express their creativity, sociability and productiveness.

However, it seems important to point out that the present study is of an exploratory nature which limits its generalizability to other settings and student populations. Therefore, to determine whether or not blogs indeed foster social interaction and student motivation to learn beyond the classroom, more research needs to be done. Nonetheless, it is hoped that this paper will provide some insights into numerous advantages of using blogs in EFL classes and inspire foreign language teachers to make use of this interesting and authentic medium of computer-based communication. 


\section{References:}

Ahluwalia, G., Gupta, D. \& Aggarwal, D. (2011): 'The Use of Blogs in English Language Learn ing: A Study of Student Perceptions', in PROFILE Vol. 13, No. 2, October 2011, Bogotá, Colombia, pp. 29-41.

Blackstone, B., Spiri, J., Naganuma, N.(2007): 'Blogs in English language teaching and learning: Pedagogical uses and student responses', in Reflections on English Language Teaching, Vol. 6, No. 2, pp. 1-20.

Blood, R. (2000). 'Weblogs: a history and perspective', http://www.rebeccablood. net/essays/web log_history.html

Campbell, A. P. (2003). 'Weblogs for use with ESL classes'. TESL Journal, IX(2). http://iteslj.org/ Techniques/Campbell-Weblogs.html

Carney, N. (2009): 'Blogging in foreign language education'. In M. Thomas (Ed.), Handbook of research on Web 2.0 and second language learning (pp. 292-312). IGI Global.

Churchill, D. (2009): 'Educational applications of Web 2.0: Using blogs to support teaching and learning', British Journal of Educational Technology, 40(1), pp. 179-183.

Dieu, B. (2004): 'Practice View: Blogs for Language Learning', in Autumn 2004 Portal (Practice) Dieu 1;, http://beespace.net/blog/wp.../autumn-2004-portal.pdf囚

Downes, S. (2004): Educational blogging. Educause review, pp. 14-20.

Ducate, L.C., Lomicka, L.L. (2008): 'Adventures in the blogosphere: from blog readers to blog writers', in Computer Assisted Language Learning, Vol. 21, No. 1, Feb 2008, pp. 9-28.

Godwin-Jones, R. (2003): 'Emerging technologies, Blogs and Wikis: Environments for On-line Col laboration', in Language Learning \& Technology, Volume 7, No.2, May 2003, pp. 12-16); http://llt.msu.edu/vol7num2/emerging/

Gunawardena, C. N., \& Zittle, F. J. (1997): 'Social presence as a predictor of satisfaction within a computer-mediated conferencing environment'. American Journal of Distance Educa tion, 11 (3), pp. 8-26.

Herring, S.C., et al. (2004): 'Bridging the Gap: A Genre Analysis of Weblogs', in Proceedings of the 37th Hawaii International Conference on System Sciences - 2004

Huffaker, D. (2004): The educated blogger: Using weblogs to promote literacy in the classroom, First Monday, Vol. 9, No. 6, http://firstmonday.org/ojs/index.php/fm/article/ view/1156/1076

Lee, L. (20011): 'Blogging: promoting learner autonomy and intercultural competence through study abroad', in Language Learning \& Technology, volume 15, No. 3, pp. 87-109; http:// llt.msu.edu/issue/october2011/lee.pdf 


\section{H. Šabanović}

Luehmann, A., MacBride, R. (2009): 'Classroom blogging in the service of student-centered ped agogy: Two high school teachers' use of blogs', in Then Journal, Issue No. 6; Summer 2009.

Morrison, A. (2008): 'Blogs and blogging: Text and Practice in A Companion for Digital Literary Studies, ed. Susan Shreibman and Ray Siemens. Oxford: Blackwell. http://www.digitalhu manities.org/companionDLS/

Moore, M. G., \& Kearsley, G. (1996): Distance education - a systems view. Belmont, CA: Wadsworth Publishing.

Nardi, B. A., Schiano, D. J., \& Gumbrecht, M. (2004): 'Blogging as social activity, or, would you let 900 million people read your diary?', in J. D. Herbsleb \& G. M. Olson (Eds.), Proceed ings of the 2004 ACM conference on Computer supported cooperative work New York, NY: ACM, pp. 222-231.

Pinkman, K. (2005): 'Using blogs in the foreign language classroom: Encouraging learner inde pendence', The JALT CALL Journal, 1(1), 12-24.

Ray, B., Hocutt, M. (2006): 'Teacher-created, Teacher-centered Weblogs: Perceptions and Practices', Journal of Computing in Teacher Education, Volume 23, Number 1 Fall 2006.

Richardson, W. (2003): 'Web logs in the English classroom: More than just chat.' English journal, 93 (1), pp. 39-43.

Richardson, W. (2006). Blogs, wikis, podcasts, and other powerful Web tools for classrooms. Thou sand Oaks, CA: Corwin Press.

Ward, J.M. (2004): 'Blog Assisted Language Learning (BALL): Push button publishing for the pu pils', TEFL Web Journal, Vol 3, No 1 2004, pp. 1-16.

Weiler, G. (2003): 'Using weblogs in the classroom, The English Journal, 92(5), 73-75.

Yang, S.-H. (2009): 'Using blogs to enhance critical reflection and community of practice', Educa tional Technology \& Society, 12(2), pp. 11-21.

Zhang, D.(2009): 'The Application of Blog in English Writing' in Journal of Cambridge Studies, Vol 4. No. 1 Mar 2009, pp. 64-72. 